\title{
Study of canthal index in Nepalese undergraduate medical students of BPKIHS, Nepal: gender and ethnic differences
}

Shah S', Koirala S ${ }^{2}$

'Sandip Shah, Assistant Professor; ${ }^{2}$ Sarun Koirala, Assistant Professor; Department of Human Anatomy, BP Koirala Institute of Health Sciences, Dharan, Nepal

\section{Abstract}

Background: Craniofacial anthropometry is a technique used in both physical and clinical anthropology comprising precise and systematic measurements of the human skull. It also includes measurement of the medial and lateral canthal distances. People of different genetic background subjected to significantly different environmental influences have different craniofacial morphology.

Objectives: To find out effect of gender and ethnicity on Canthal anthropometry.

Methods: This descriptive cross-sectional study was carried out to determine and compare canthal anthropometry among 299 undergraduate students (Male=161, Female=138) of different ethnic groups (Indo-Nepalese, indigenous and Tibeto-Nepalese) of age group 19-21 years at BPKIHS. Medial and lateral canthal distances were measured by using straight vernier caliper and canthal index (medial canthal distances / lateral canthal distance $\times 100$ ) for all three ethnic groups in both sexes were compared.

Results: The study has shown that the female students had higher canthal index than male students $(27.65 \pm 12.35$ vs 23.96 \pm 5.76$)$. When compared on the basis of ethnicity, Indo-Nepalese had highest value of canthal index followed by Indigenous and Tibeto-Nepalese.

Conclusion: In conclusion, genetics and environmental factors are responsible for the variation in canthal indices and other craniofacial indices between and within populations. Therefore, its standard values are largely applicable for clinical assessment of patients with syndrome affecting canthal anatomy.

Key words: Anthropometry, Canthal index, Genetics

\section{INTRODUCTION}

$\mathrm{N}^{2}$ epalese society is ethnically diverse and complex in phenotype (physical characteristics) and culture ranging between Indian to Tibetan population. Except for sizeable population with Indian birth or ancestry concentrated in the Terai bordering India, the varied ethnic groups evolve into distinct patterns over time'.

Political scientists, Joshi and Rose, broadly classify the Nepalese population into three major ethnic groups in terms of their origin: Indo-Nepalese (IND), TibetoNepalese (TN) and Indigenous (IN). In case of first two groups, the direction of their migration and Nepal's landscapes appeared to have led to their vertical

Address for correspondence

Dr. Sandip Shah

Assistant Professor

Department of Human Anatomy

BP Koirala Institute of Health Sciences, Dharan, Nepal

E-mail: San230dip@yahoo.com distribution. The first group comprising those of IndoNepalese origin inhabits the more fertile lower hills, river valleys and Terai plains adjoining boundary of India. The second major group consists of communities of Tibeto-Nepalese origin occupying the higher hills from west to east of Nepal. The third and much smaller group comprises of a number of tribal communities, such as the Tharus and the Dhimal of the Terai who may represent the characteristics of both Indo-Nepalese and Tibeto-Nepalese².

Anthropometry is concerned with measurement of physical sizes and shapes of human body ${ }^{3}$. Craniofacial anthropometry is an integral part of craniofacial surgery and syndromology ${ }^{4}$. It is a technique used in both physical and clinical anthropology comprising precise and systematic measurements of the human skull ${ }^{5}$. Peoples of different genetic background subjected to significantly different environmental influences have different craniofacial morphology ${ }^{6}$. 
Craniofacial anthropometry also includes measurement of the medial and lateral canthal distances to find out canthal index. It is important for the study of human growth and variations in different races and also for clinical diagnosis and treatment ${ }^{7}$.

Accurate values of these standards are essential guide to both constructive surgeries and orthodontic treatment because illusory hypertelorism may occur in individual nasal bridge, epicanthal folds, extopia, widely placed eyebrows, narrow palpebral fissure and dystonia canthonum ${ }^{8}$.

No such study has assessed the relationship of canthal anatomy with gender and ethnic variations in Nepalese population. Thus the aim of this study is to find out the effect of gender and ethnicity on canthal anthropometry which will be of importance in clinical practices, forensic anthropology, genetics and paleoanthropological studies.

\section{METHODS}

This descriptive cross-sectional study was carried out to determine and compare canthal anthropometry among 299 undergraduate students (Male $=161$, Female=138) of different ethnic groups (Indo-Nepalese, Indigenous and Tibeto-Nepalese) of age group 19 to 21 years. The study was carried out between June and December, 2012 after obtaining ethical clearance and research permission as per as rule of the institute.

\section{Inclusion Criteria:}

- Healthy participants of pure ethnic races of age group of 19-21 years.

- Undergraduate students of BP Koirala Institute of Health Sciences, Nepal holding Nepalese citizenship.

\section{Exclusion Criteria:}

- Participants with any craniofacial injury or deformity or syndromes.

- Participants with chronic systemic diseases.

- Undergraduate students of foreign nations.

- Participants having family history of intercaste marriage.
- Participants who did not wish to take part in the study.

Random sampling was done for data collection for the respective ethnic races. Informed consent was taken following which a questionnaire was filled up by the participants, which consisted of general information along with related craniofacial measurements. The participants were initially oriented to the purpose of the study and assured that anonymity would be maintained. Then they were seated comfortably on the chair in a relaxed state in an upright position against the head rest. The medial canthal distance (MCD) was measured from the medial angle of palpebral fissure in $\mathrm{mm}$ by straight vernier caliper without application of pressure. The lateral canthal distance (LCD) was measured from the lateral angle of left eye to lateral angle of right eye in $\mathrm{mm}$. Canthal index $(\mathrm{Cl})$ was then calculated as medial canthal distance/ lateral canthal distance $\times 100$. Data obtained from each participant was recorded in a special form and then transferred to Microsoft Excel software. The data collected was tabulated and analysed using Statistical Package for Social Sciences (SPSS) 15.0 version software. One way ANOVA and independent $t$ test were used to compare the mean among different groups and a $p$ value $<0.05$ was considered significant.

\section{RESULTS}

The mean age of all participants was 20.2 years. Among 299 undergraduate students, the male participants were 161 and female participants were 138. The IndoNepalese, Indigenous and Tibeto-Nepalese participants were 142, 81 and 76 respectively. The obtained data in sampled participants were summarized as below in tabulated form. Significant gender and ethnic differences were found in LCD and in $\mathrm{Cl}$ but not in MCD.

Table 1: Mean of all the Anthropometric parameters

\begin{tabular}{lc}
\hline Parameters & Mean \\
\hline Age & 20.2 years \\
Medial canthal distance & $2.49 \mathrm{~mm}$ \\
\hline Lateral canthal distance & $10.10 \mathrm{~mm}$ \\
Canthal index & 25.37 \\
\hline
\end{tabular}

Table 2: Mean and SD of all Measured Anthropometric Parameters for males and females participants

\begin{tabular}{lccc}
\hline Parameters & Males $(\mathbf{n}=\mathbf{1 6 1})$ & Females $(\mathbf{n}=\mathbf{1 3 8})$ & p-value \\
$\mathrm{MCD}^{*}$ & $2.48 \pm 0.54 \mathrm{~mm}$ & $2.51 \pm 0.29 \mathrm{~mm}$ & 0.51 \\
$\mathrm{LCD}^{\dagger}$ & $10.44 \pm 0.52 \mathrm{~mm}$ & $9.56 \pm 1.12 \mathrm{~mm}$ & $<0.001$ \\
$\mathrm{Cl}^{\ddagger}$ & $23.96 \pm 5.76$ & $27.65 \pm 12.35$ & 0.04 \\
\hline
\end{tabular}

$\mathrm{p}$ value calculated by $\mathrm{t}$ test.

*Medial canthal distance, ${ }^{+}$Lateral canthal distance, ${ }^{*}$ Canthal index 
Table 3: Mean and SD of all Measured Anthropometric Parameters among all ethnic groups

\begin{tabular}{lcccc}
\hline Parameters & Indo-Nepalese $(\mathbf{n}=\mathbf{1 4 2})$ & Indigenous $(\mathbf{n}=\mathbf{8 1})$ & Tibeto-Nepalese $(\mathbf{n}=\mathbf{7 6})$ & $\mathbf{p}$-value \\
$\mathrm{MCD}^{*}$ & $2.51 \pm 0.49 \mathrm{~mm}$ & $2.50 \pm 0.28 \mathrm{~mm}$ & $2.38 \pm 0.35 \mathrm{~mm}$ & 0.82 \\
$\mathrm{LCD}^{\dagger}$ & $10.99 \pm 0.94 \mathrm{~mm}$ & $10.01 \pm 0.80 \mathrm{~mm}$ & $8.93 \pm 0.75 \mathrm{~mm}$ & 0.03 \\
$\mathrm{Cl}^{\ddagger}$ & $25.92 \pm 9.80$ & $24.03 \pm 3.93$ & $23.14 \pm 4.05$ & 0.04 \\
\hline
\end{tabular}

$\mathrm{p}$ value calculated by one way ANOVA test.

* Medial canthal distance, ${ }^{\dagger}$ Lateral canthal distance, ${ }^{\ddagger}$ Canthal index

\section{DISCUSSION}

Craniofacial anthropometry is important in the evaluation of facial trauma, facial defect, congenital and post traumatic deformities, easy identification of certain congenital malformation, and diagnosis of hypo/hypertelorism. Comparative analysis of canthal parameters across different populations is yet to establish a consistent pattern of gender and ethnic differences. The normal values of medial and lateral canthal distances and canthal index are important for successful reconstruction of the canthal area?.

In 2008, the study conducted in Africa showed canthal index of male ljaws and Igbos were 37.04 and 35.15, respectively and female ljaws and Igbos were 33.11 and 32.59 , respectively ${ }^{10}$. The various study had reported relatively greater mean values for $M C D$ and $L C D$ for males as compared to females in studies carried out among subjects of Turkish and Latvian population ${ }^{11,12}$. In our study, mean LCD of male was found to be higher than female participants but mean MCD was higher in female participants when compared with males.

The study (2002) conducted on a population of Saudi Arabian subjects, showed a greater average value for females in MCD as compared to their male counterparts as in present study ${ }^{13}$. Gender differences in canthal measurements are attributable to genetic and environmental factors, as are differences seen across age and ethnic background ${ }^{14}$.

The participants of our present study were younger and of a closer age cohort than those of similar studies among the Nigerian groups. Younger populations tend to have lower values of MCD, LCD and $\mathrm{Cl}$ in comparison to older populations and generally, canthal measurements become constant in the third decade of life $\mathrm{e}^{15}$.

Similarly study carried out in Turkey reported the inner canthal distance, outer canthal distance and canthal index of $28.33 \mathrm{~mm}, 81.74 \mathrm{~mm}$ and 34.66, respectively for Turkish males while those of females were 28.14, 81.17 and $34.6 \mathrm{~mm}$, respectively ${ }^{16}$. In the study conducted in
Gujarat, India, mean Cl was found to be 33.10 and 33.10 in males and females respectively, which was again higher than our ethnic groups ${ }^{17}$.

When compared on the basis of ethnicity, IndoNepalese had highest value of canthal index followed by Indigenous and Tibeto-Nepalese. In the present study, statistically significant ethnic differences were found in LCD and in $\mathrm{Cl}$ but not in MCD.

Indeed, dysmorphic craniofacial features may be apparent in individuals with syndromic conditions such as Apert's, Crouzon's, Robinson's syndromes, trisomy 13, Williams, and the Meckel-Gruber syndromes. In unaffected family relatives who may harbour subtle facie, benefit from genetic counselling may require, as a screening procedure, measurements of the craniofacial parameters. These parameters may also be useful for preliminary identification purposes in settings were robust forensic procedures are in limited supply ${ }^{14}$.

Thus, the present study has provided normative data of canthal anthropometric parameters in Nepalese population which reflects the potentially different patterns of craniofacial growth resulting from racial, ethnic, sexual and dietary differences.

\section{CONCLUSION}

In conclusion, genetics and environmental factors are responsible for the variation in canthal indices and other craniofacial indices between and within populations. The result of this study will be very useful in forensic medicine, surgery, ophthalmology and anthropology and will also serve as a future framework for estimating the canthal index of Neplaese population.

\section{ACKNOWLEDGEMENT}

The authors acknowledge the support and assistant given by the Department of Human Anatomy, BP Koirala Institute of Health Sciences, Nepal; the participants and other individuals to ensure the successful completion of this study. 


\section{REFERENCES}

1. National Population and Housing Census 2011 (National Report) Central Bureau of Statistics (Nepal). [Internet]. [cited 2012 Nov 26]. Available from:http://en.wikipedia.org/wiki/Demographic of Nepal.htm.

2. Joshi BL, Rose LE. Nepal-Caste and Ethnicity [Internet]. 1991 Sep. Available from: http://www. photius.com/countries/nepal/society/nepal_ society_caste_and_ethnicity.html

3. Basciftci FA, Uysal T, Buyukerdmen A. Craniofacial structure of Anatolian Turkish adults with normal occlusions and well balanced face. Am J Orthod Dentofacial Orthop. 2004;125(3):366-72.

4. Farkas LG, Posnick JC, Hreczko TM,Pron GE. Growth patterns in orbital region. Cleft Palate Craniofac J. 1992;29:315-8.

5. Mahfouz KJ. Craniofacial anthropometry of a group of resident of New Delhi in India. 1988;33:243-7.

6. Kasai K, Richards LC, Brown T. Comparative study of craniofacial morphology in Japanese and Australian aboriginal populations. Hum Biol. 1993;65(5):82134.

7. Poswillo D. Casual mechanism for craniofacial deformity. J Trop Pediatr. 1963;44:973-77.

8. Cohen MM, Costa AR, Gulon A. Hypertelorism interorbital growth and pathogenetic consideration. J Oral Maxillofac Surg.1995;24:387-95.

9. Juberg RC, Sholte FG, Touchstone WJ. Normal values for intercanthal distance of 5-11 old American Blacks. Acta Pediatr.1975;55:431-36.
10. Oladipo GS, Olotu EJ, Gwurineama IU. Anthropometric comparison of canthal indices between the ljaw and Igbo tribes. Sci Afr. 2008;7(1):141-4.

11. Evereklioglu C, Doganay S, Hamdi ER, Gunduz A, Tercan M, Balat A, Cumurcu T. Craniofacial anthropometry in a Turkish population. Cleft Palate Craniofac J. 2002;39(2):208-18.

12. Nagle $E$, Teibe U, Kapoka D. Craniofacial anthropometry in a group of healthy Latvian Residents. Acta Medica Lituanica. 2005;12(1):47-53.

13. Abdullah MA. Inner Canthal distance and geometric progression as a predictor of maxillary central incisor width. J Prost Dent. 2002;88(1):16-20.

14. Oyinbo CA, Fawehinmi HB, Dare NW, Berezi MA. Normal inner and outer measurements of the ljaws of Southern Nigeria. Eur J Sci Res. 2008;22(2):163-7.

15. Fledalius HC, Stubgaard $M$. Changes in eye position during growth and adult life as based on exophthalmometryinterpupillary distance and orbital distance measurement. Acta Ophtamol. 1986;64(5):481-6.

16. Cem E, Cengiz Y, Hamdi E, Selim D, Yasar D. Normative values of craniofacial measurements in idiopathic benign microcephalic children. Cleft Palate Craniofac J.2001;38(3):260-3.

17. Patel JR, Sethuraman R, Navin YG, Mithul HS. A comparative evaluation of relationship of inner canthal distance and inner-alar width to the inter canine with amongst Gujarati population. J Adv Oral Res. 2011;2(3):111-8. 